\title{
Serological Detection of the Thermoactinomyces vulagris Antigen in Farmer's lung disease Patients using ELISA method
}

\author{
Basima A. Abdulla; Essra G. Al-Sammak and Anmar A. Al-Taie \\ Biology Dep., College of Science, Mousal University
}

\begin{abstract}
Serological detection of $\operatorname{IgG}$ antibodies to antigens one soil isolate of thermophilic actinomycetes belonged to the species Thermoactinomyces vulgaris in (70) sera of patients with farmer's lung disease and hay fever patients compared with control normal peoples in the same environmental condition were carried out using ELISA method. The results indicated that (19) sera from symptomatic patients having IgG level between (1.007-1.626) I.U/ml, four of them having farmer's lung disease and the remaining have hay fever as diagnosed by clinical. The IgG level between (0.293-0.944) I.U/ml indicated negative and which was found in(16) patients two of them having farmer's lung disease and the remaning have hay fever. The IgG level of normal people were devided in two groups: first account positive control was between (1.089-2.147) I.U/ml and the second account negative was between (0.819$0.959) \mathrm{I} . \mathrm{U} / \mathrm{ml}$.

The present study has demonstrated the usefulness of estimation of specific IgG antibodies activity to thermophilic actinomyces by ELISA for the diagnosis of farmer's lung disease as a screening test of large number of samples with sufficient high sensitivity.
\end{abstract}

Keyword: Thermoactinomyces vulagris, Antigen,lung disease, ELISA

\section{INTRODUCTION}

Hypersensitivity pneumonitis (Hp) is not a uniform disease entity, but rather a complex dynamic clinical syndrome that varies in its initial presentation and clinical course, resulting in the emergence of different patterns of disease over time. Hp has been described as occurring in acute, sub acute and chronic forms. The acute form manifests as recurrent episodes of dyspnoea and cough with fever, chills and malaise occurring about $4-8 \mathrm{~h}$ after exposure to antigens, and usually resolving within about $24-48 \mathrm{~h}$, lung function tests typically show a restrictive defect with reduced gas diffusion and hypoxaemia, and a chest radiography may show alveolar shadowing(Calvert et al., 1999). The chronic form was characterized by the insidious development of dyspnoea and pulmonary fibrosis in patients that have not experienced acute symptoms.

The subacute form is similar to the chronic form in that dyspnoea develops insidiously, but these patients also have discrete episodes of acute symptoms after antigens exposure. Classification of HP into acute and chronic forms has tended to cause confusion as it is often assumed that there is an inveitable progression from acute to chronic disease if antigen exposure continues (Bourke et al., 2001).

Farmer's lung disease (FLD), the most common form of extrinsic allergic alveolitis is a pulmonary disease with symptoms of dyspnea and cough resulting from repeated exposure to high concentration or prolonged exposure to low concentrations of inhaled antigens from moldy hay or straw, both of which lead to 
sensitization and development of this disease. Its diagnosis has most often relied on an array of nonspecific clinical symptoms and signs developed in an appropriate setting, with the demonstration of interstitial marking on chest $\mathrm{x}$-ray, serum precipitins against offending antigens, lymphocytic alveolitis on bronchoalveolar lavage, and or agranulomatous reaction on lung biopsies (Reboux et al., 2001).The thermophilic actinomycetes are responsible for hypersensitivity pneumonitis, an allergic reaction to these agents. This occupational disease occurs in farmers, factory workers, and others who are repeatedly exposed to these agents, there are acute and chronic forms of this disease. Acute hypersensitivity pneumonitis typically symptoms resolve within a day and a continued exposure to the organisms form a chronic disease in which symptoms progressively worsen with subsequent development of irreversible lung fibrosis (Forbes et al., 1998).

The genus Thermoactinomyces spp. was one of the earliest known actinomycete taxa that was first proposed with Thermoactinomyces vulgaris, the type species of the genus, there was no doubt in recognizing Thermoactinomyces species as actinomycetes because of their morphological characteristics of forming aerial and substrate mycelia. Thermoactinomyces was thermophilic grows between $\left(45\right.$ and $60^{\circ} \mathrm{C}$ ) and forms single spores on both its aerial and substrate mycelia, it is commonly found in damp hay stacks, compost piles and other high-temperature habitate, unlike other actinomycete spores.

Spores of Thermoactinomyces spp. are true endospores and very heat-resistant, they can survive at $90^{\circ} \mathrm{C}$ for more than 30 minutes, they are formed within the hyphae and appear to have typical endospore, gram positive, aerobic and saprophytic chemorganotrophic utilize a range of sugars and are able to degrade various polymeric substrates (Holt et al., 1994). However, some studies provided evidence that the genus Thermoactinomyces spp. should no longer be classified within the order Actinomycetales (Yoon and Park, 2000).

Thermoactinomyces species produce endosproes as shown in bacilli and have lower $\mathrm{G}+\mathrm{C}$ contents than those of actinomycets. 16sr RNA oligonucleotide sequencing revealed that the genus Thermoactinomyces is more closely related to Bacillus species than to actinomycetes and should be placed within the family Bacillaceae (Prescott et al., 2008).

Identifying the etiological agents is of primary importance for the immunological diagnosis of this disease.It is also a necessary step in the development of preventive methods. Saccharopolyspora rectivigula and Thermoactinomyces vulgaris remain the main recognized etiologies of FLD, other bacterial and fungal species have been demonstrated or suspected to play a role in FLD (Reboux et al., 2001).

The aim of this work to estimate the specific IgG antibody using ELISA in sera of patients with famer's lung disease in farmer's workers compared with hay fever patient's and control people.

\section{MATERIALS AND METHODS}

Cahort study was carried out from April 2007 to April 2008 in Iraq (Mosul).Thirty five sera from males and females patients, five of them having farmer's lung disease and thirty with hay fever attending the private clinic in Mosul. Protocol for diagnosis of farmer's lung disease by serology was cared out using IgG ELISA Euroimmun.

Antibody of Thermophilic bacterial antigen belongs to one soil isolate of the species Thermoactinomyces vulagris was carried out as the flowing: 


\section{Preparation of Thermoactinomyces vulgaris antigen:}

Bacteria was cultured in trypticase soy agar with $2 \%$-Glycerol in $\mathrm{pH} 7.0$ for $3-5$ days in $45^{\circ} \mathrm{C}$. Bacterial growth was harvested by centrifugation at 3000 cycle for 10 min and washed 2 times with sterile phosphate buffer saline (PBS in $\mathrm{pH} 7.3$ ). Two milliliters of the bacterial pellet was resuspended in $10 \mathrm{ml}$ of PBS. Sonicated (in 24,000 Ampudance/sec) $5 \mathrm{sec}$. to each cycle between each cycle $1 / 2 \mathrm{~min}$. modified from (Kohler et al., 2003).

$1-100 \mu \mathrm{L}$ of antigen was dispensed in to desirved number of coated wells in to the holder and incubated in $45^{\circ} \mathrm{C}$ to 24 hours.

2-1:40 diluted of serum negative and positive control was dispensed into the appropriate wells.

3 -Incubate at $37^{\circ} \mathrm{C}$ for 30 minutes.

4- The liquid from all wells was removed at the end of incubation. Wells was rinsed and flicked the microtiter wells 4 times with diluted wash buffer (1x).

5- Liquid from all wells was disposed by trapping it in absorbent paper with the openings facing downwards to remove all residual wash buffer.

6- $100 \mu \mathrm{L}$ of enzyme conjugate (peroxidaselabelld anti-human $\operatorname{IgG}$ )was dispensed into each wells and incubated for 30 minutes of room temperature.

7- Wells was washed as described above in step 4.

8- $100 \mu \mathrm{L}$ chromogen (substrate) solution was dispensed into each wells and incubate for 15 minutes at room temperature (protect from direct sunlight).

9- $100 \mu \mathrm{L}$ of stop solution $(1 \mathrm{~N} \mathrm{HCl})$ to stop reaction.

10-Photometric measurement of the O.D was carried at wavelength of 450 $\mathrm{nm}$ and areference wave of between $620 \mathrm{~nm}$ and $650 \mathrm{~nm}$ within 30 minutes after adding the stop solution with amicro wells reaction. Prior to measuring slightly shake the microplate to ensure a homogeneous distribution of the solution.

\section{RESULTS}

The cut value of positive results is 1.0 but less than 1.0 indicated negative results. Specific antibody activities to Therm. vulgaris at level between (1.007-1.626) I.U/ml for the group of the patients with symptoms, But level between (0.293-0.944) I.U/ml indicated no antibody in the patient's serum with symptoms in the same group. level between (1.089-2.147) I.U/ml for the control (+) group, but the level between (0.819-0.959) indicate no antibody for the control (-)group.

All patients from the city and age (19-30\&31>) for females and males.

Table (1): Titer of antibody to Thermoactinomyces vulgaris with their age groups in patients under study

\begin{tabular}{|l|c|c|}
\hline \multicolumn{1}{|c|}{ Groups } & Titer & Num \\
\hline 4 farmer's & 1.007 & 19 \\
\hline 15 hay fever & 1.626 & \\
\hline Symptomatic no antibodies (14) & 0.293 & 16 \\
hay fever (2) farmer's lung & 0.944 & \\
\hline Control with antibody + & 1.089 & 25 \\
& 2.147 & \\
\hline Control with no antibody - & 0.819 & 10 \\
& 0.959 & \\
\hline total & & 70 \\
\hline
\end{tabular}

Patients: 23-female

12- male

\section{DISCUSSION}

Hypersensitivity penumonitis HP can be provoked by adiverse array of antigens including bacteria, fungi, animal proteins, avian and chemical (Hanak et al. 2007).Geographical, social and occupational factors determine the particular types of HP found throughout the world, because of the great variety and distribution of these antigens, many individuals are exposed to potential causes of this syndrome as part of their occupational, home or recreational environments (Bourke et al., 2001).

There is adiverse array of antigens that provoke HP which share certain important characteristics that distinguish them from other antigens that provoke asthma for example, and not all inhaled antigens have the capacity to provoke HP. These characteristics include their size, solubility, particulate nature and their 
capacity to provoke a nonspecific inflammatory response and specific immune reaction. Antigens provoking $\mathrm{HP}$ are usually $23 \mu \mathrm{m}$ in diameter and can be inhaled into the distal bronchial tree and alveoli, where they may be cleared via local lymphatic drainage to the hilar nodes, which seems to be important in inducing an immunoglobulin-G type III IgG response (Kaltreider et al. 1977). In contrast antigens more typically associated with asthma are larger than $30 \mu \mathrm{m}$ in diameter and are preferentially deposited in the proximal air way where they tend to provoke an IgE antibody response in a topic subjects (Vandenplas et al. 1993).

A single antigen may sometimes produce both types of response and larger particls may reach the alveoli after degradation or being dissolved in lung secretions. The antigens of HP also have powerful adjuvant properties with a capacity to activate complement by the alternative pathway, to stimulate alveolar macrophages and to enhance delayed cellular responses (Yoshizawa et al. 1988). The presence of so - called a symptomatic healthy farmers with IgG antibody has been pointed out by several investigators (Barboriak et al., 1973; Banaszak et al., 1974; Konishi et al., 1985 and Bourke et al. 2001).

There is a possibility that Therm. vulgaris in not necessarily a causative antigen as in the study of (Konishi et al., 1985). Concentration of an antigen rather than the length of period to inhale an antigen may contribute to the development of circulating antibodies of FLD.

The prevalence farmer's lung disease has been reported to range from 10-200 / 100,000 general population and 4-170 /1000 farmers (Hanak et al., 2007) and a characteristic feature of HP is that only $5-15 \%$ of subjects exposed to a provoking antigen develop the disease (Bourke et al., 2001). Warren,
1977 showed that antibodies against these thermophilic actinomycetes in particular Micropolyspora faeni and sometimes Thermactinomyces vulgaris were found in $80 \%$ of patients with farmer's lung but they were also found in $20 \%$ of healthy farmers, they indicated only exposure to the thermophilic actinomyces detection of such antibody should be considered as a diagnostic only in the appropriate clinical context. In the study of (Reboux et al., 2001) using enzyme linked immunosorbent assay (ELISA) method, they were found a level of IgG against Absidia corymbifera of three times higher in farmers with FLD than in exposed control farmers. Although, asymptomatic exposed individuals also may show elevated levels of antibodies (Kurup et al., 2006). In the study of (Dutkiewicz et al., 2001) using agar-gel precipitation test there is a small differences in the level of $\operatorname{IgG}$ antibody to the Th. vulgaris antigen in the symptomatic and asymptomatic sawmill worker, It must be clearly distinguished from a number of nonallergic, inflammatory reactions such as late asthmatic reactions, toxic alveolitis and organic dust toxic syndrome, which are also associated with the inhalation of organic dusts.

These reactions typically occur after a single exposure to an unusually high level of organic dust and they may occur in naive subjects without previous exposure, in such toxic reactions, individual susceptibility is less apparent and all subjects that have the same degree of exposure develop a similar clinical illness (Calvert et al. 1999). Individual susceptibility is a characteristic feature of an immunemediated disease such as HP that only a small percentage of those exposed to the antigen develop the diseases in the patients who develop the disease have some susceptibility and the interaction between host and antigen is influenced 
by both genetic and environmental factors (Bourke et al., 2001).

\section{CONCLUSIONS}

The present study has demonstrated the usefulness of measurement of $\operatorname{IgG}$ antibody activity to thermophilic actinomycetes by ELISA for the diagnosis of FLD particularly as a screening test of a large number of samples. The procedure is simple and much less time-consuming than the conventional double imminodiffusion method, and is considered and excellent method with sufficiently high sensitivity The demonstration of an antibody reaction against the provoking antigen may assist establishing the diagnosis, but such antibody reaction are not present in all cases of FLD and they lack specificity for the disease because they are present in asymptomatic subject exposed to the antigen.

\section{REFERENCES}

Banaszak, J. J.; Barboriak, J.; Fink, J.; Scanlon, G.; Schlueter, D. P.; Sosman, A.; Thiede, W. and Unger, G. (1974). Epidemiological studies relating thermophilic fungi and hypersentivity lung syndrome. Amer. Rev. Resp. Dis., 110: 585-591.

Barboriak, J. J.; Fink, J. N.; Sosman, A. J. and Dhaliwal, K. S. (1973). Precipitating antibody against pigeon antigens in sera of asymptomatic pigeon breeders. J. Lab. Clin. Med., 82:372376.

Bourke, S. J.; Dalphin, J. C.; Boyed, G.; McSharry, C.; Baldwin, C. I. and Calvert, J. E. (2001). Hypersentivity Penumonitis: Current concepts., Eur. Respire. J., 32: 81-92.

Calvert, J. F.; Baldwin, C. I.; Allen, A.; Todd, A. and Bourke, S. J. (1999) Pigeon fancier's lung: acomplex disease. Clin. Expt. Allergy., 29:166-175.

Dutkiewicz, J.; Skorska, C.; Traczyk, E. K.; Dutkiewicz, E.; Matuszyk, A. and Sitkowska, J. (2001). Response of Sow mill workers to work related airborne allergens. Ann. Agric. Environ. Med., 8: 81-90.

Forbes, B. A.; Sahm, D. F. and Weissfeld, A. S. (1998). Bailey \& Scott's Diagnostic Microbiology. $8^{\text {th }}$ ed. time Mirror Company Mosby, Inc., U.S.A.

Hanak, V.; Golbin, J. M. and Ryu, J. H. (2007). Causes and presenting features in 85 consecutive patients with hypersensitivity penumonitis., Mayo. Clin. Proc., 82 (7): 812-816.
Holt, J. G.; Krieg, N. R.; Sneath, P. H. A.; Staley, J. T. and Williams, S. T. (1994). Bergey's Manual of Determinative Bacteriology. $9^{\text {th }}$ ed. Williams and Wilkins. Baltimore., pp. 605-703.

Kaltreider, H. B.; Caldwell, J. L. and Adam, E. (1977). The fate and consequence of an organic particulate antigen instilled into bronchoalveolar spaces of canine lungs. Am. Rev. Respir. Dis, 116:267-280.

Kohler, A.; Stone, D. M.; Hines, M. T.; Byrne, B. A.; Alperin, D. C.; Norton, L. K. and Hines, S. A. (2003). Rhodococcus equi secreted antigens are immunogenic and stimulate a type 1 call response in the lung of horses immune to $R$. equi infection. Infection and Immunoty., 71(11):6329-6337.

Konishi, K.; Murakami, S. and Kokubu, K. (1985). Determination by enzymelinked Immunosorbent Assay (ELISA) of specific IgG antibody activities for diagnosis of farmer's lung disease. Tohoku. J. Exp. Med., 147: 135-144.

Kurup, V. P.; Zacharisen, M. C. and Fink, J. N. (2006). Hypersentivity penumonitis. The Indian Journal of Chest Disease \& Allied Sciences., 48: 115-128.

Prescott, L. M.; Harley. J. P. and Klein, D.A. (2008). Microbiology. $6^{\text {th }}$ ed. McGraw-Hill Companies, Inc. Americas, New York.

Reboux, G.; Piarroux, R.; Mauny, F.; Madroszyk, A.; Millon, L.; Bardonnet, K. and Dalphin, J. (2001). Role of Molds in farmer's lung disease in Eastern France. Am. J. Respir., Crit. Care Med., 163:15341539.

Vandenplas, O.; Malo, J. L. and Dugas, M. (1993). Hypersensitivity pneumonitis-like reaction among workers exposed to piphenylmethane diisocyanate (MDI). Am. Rev. Respir. Dis., 147: 338-346.

Warren, C. P. W. (1977). Lung disease in farmers CMA. J., 116: 391-394.

Yoon, J. and Park, Y. (2000). Phylogenetic analysis of the genus Thermoactinomyces based on $16 \mathrm{~s}$ rDNA sequences. Int. J. Sys. Evol. Microiol., 50: 1081-1086.

Yoshizawa,Y.; Nomura, A.; Ohdama, S.; Tanaka, M.; Morinari, H. and Hasegawa, S. (1988). The significance of complements activation in the pathogenesis of hypersensitivity pneumonitis. Int. Arch. Allergy. Appl. Immunol, 87:417- 423. 


\section{ARABIC SUMMARY}

التحري مصليا عن مستضد Thermoactinomyces vulgaris لاى الفلاحين المتحسين رئويا في الموصل

$$
\text { باسيهة احمد عبد الله - .اسراء غانم السماك ـ ـانمار احمد الطائي }
$$

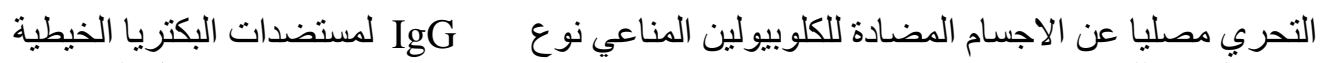

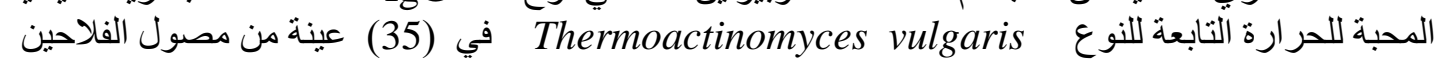

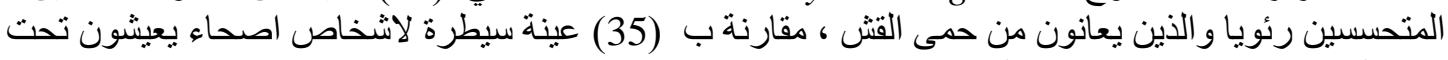
نفس الظروف باستخدام طريقة الاليز ا.

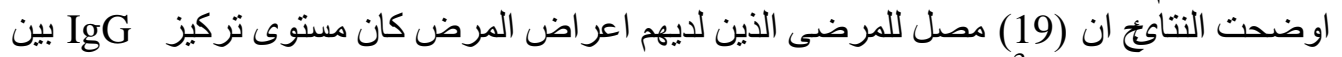

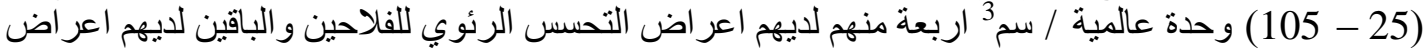

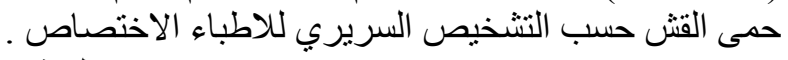

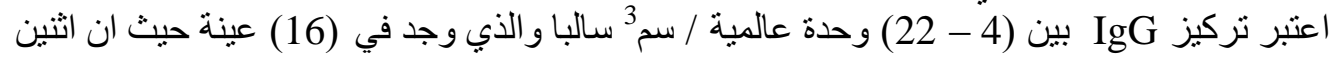

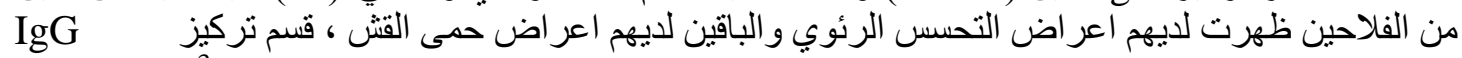

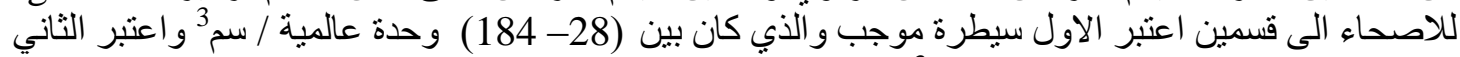

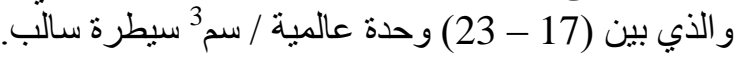

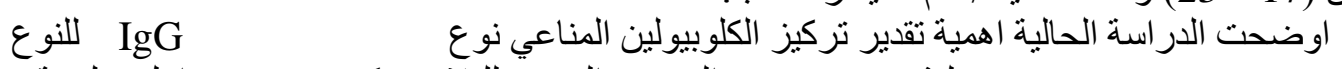

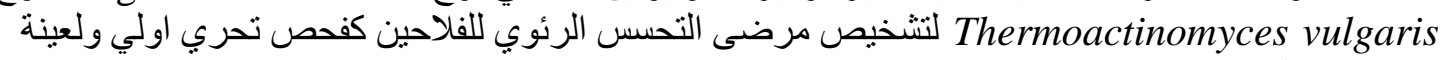
و اسعة من المرضى. 